Audiology

Neurotology
Audiol Neurotol 2012;17:395-399

DOI: $\underline{10.1159 / 000341160}$
Received: February 14, 2012

Accepted after revision: June 11, 2012

Published online: August 25, 2012

\title{
Long-Term Follow-Up of Implanted Children with Cytomegalovirus-Related Deafness
}

\author{
Marika Viccaro Roberto Filipo Ersilia Bosco Maria Nicastri Patrizia Mancini \\ Department of Sense Organs, Sapienza University of Rome, Rome, Italy
}

\section{Key Words}

Congenital cytomegalovirus infection - Cochlear implant • Long-term follow-up

\begin{abstract}
Objective: To evaluate, with a long-term follow-up, the speech perception and language development in children with cytomegalovirus (CMV)-related deafness after cochlear implantation. Study Design: A retrospective study on CMVrelated profound deafness and cochlear implantation was performed from 1995 to 2010. Six children with an average follow-up of 10 years were included in this research. Medical history, imaging, cognitive delay, speech perception and production data were reviewed. Results: Two of the 6 patients developed a functional language with the use of phrases and word sequences based on morphological and syntactic rules; the others demonstrated the development of a preverbal or transitional language with the use of single words only. Conclusion: Patients with CMV-related deafness benefit from cochlear implantation; however, the expectations of the parents must be evaluated in a series of counseling efforts prior to the surgery.
\end{abstract}

Copyright $\odot 2012$ S. Karger AG, Basel
(C) 2012 S. Karger AG, Basel

$1420-3030 / 12 / 0176-0395 \$ 38.00 / 0$

Fax +4161306 1234

E-Mail karger@karger.ch

www.karger.com
Accessible online at:

www.karger.com/aud

\section{Introduction}

Cytomegalovirus (CMV) is still one of the most common and important intrauterine viral infections in developed countries today, affecting approximately $0.5-2.5 \%$ of all live births [Hagay et al., 1996]. Approximately $10 \%$ of congenitally infected infants are symptomatic at birth for developing the congenital CMV syndrome [Stagno and Whitley, 1985]. The remaining 90\% with asymptomatic congenital CMV appear clinically normal at birth. However, later complications such as sensorineural hearing loss (SNHL), mental retardation, delay in psychomotor development, learning disabilities and expressive language delay are reported in association with more than $90 \%$ of these patients [Stagno et al., 1977]. SNHL is a common manifestation of the congenital CMV infection, affecting $20-60 \%$ of symptomatic and $15-25 \%$ of asymptomatic infants [Fowler et al., 1999; Iwasaki et al., 2007; Grosse et al., 2008]. Several authors noticed that SNHL becomes more severe after the 1st year of life [Huygen and Admiral, 1996], with a further deterioration within the first 4 years of life (progressive hearing loss) [Hickson and Alcock, 1991; Williamson et al., 1992]. The proposed mechanism for CMV-associated SNHL appears to be the direct infection of the otic capsule. CMV antigens have been detected in the organ of Corti, the auditory nerve, 
Table 1. Patient characteristics and CMV-associated symptoms

\begin{tabular}{|c|c|c|c|c|c|c|c|c|c|}
\hline Patients $(n=6)$ & Clinical signs at birth & $\begin{array}{l}\text { MRI } \\
\text { calcifi- } \\
\text { cation }^{\text {a }}\end{array}$ & $\begin{array}{l}\text { Motor } \\
\text { impair- } \\
\text { ment }\end{array}$ & $\begin{array}{l}\text { Prema- } \\
\text { turity }\end{array}$ & $\begin{array}{l}\text { Visual } \\
\text { impair- } \\
\text { ment }\end{array}$ & $\begin{array}{l}\text { Cognitive } \\
\text { impair- } \\
\text { ment }^{\text {b }}\end{array}$ & Hearing loss onset & $\begin{array}{l}\text { Age at } \\
\text { im- } \\
\text { plant }\end{array}$ & $\begin{array}{l}\text { CI } \\
\text { use in } \\
\text { years }\end{array}$ \\
\hline P1 symptomatic & microcephaly & yes & yes & no & no & 90 & congenital profound & 4 & 15 \\
\hline P2 asymptomatic & none & no & no & no & no & 100 & congenital profound & 3 & 11 \\
\hline P3 symptomatic & seizures & yes & yes & no & no & 70 & congenital profound & 3 & 9 \\
\hline P4 symptomatic & thrombocytopenia, petechiae & yes & yes & no & no & 100 & congenital profound & 2 & 10 \\
\hline P5 asymptomatic & none & no & no & no & no & 100 & progressive & 10 & 7 \\
\hline P6 symptomatic & seizures, thrombocytopenia & yes & yes & no & no & 70 & progressive & 3 & 8 \\
\hline
\end{tabular}

$\mathrm{CI}=$ cochlear implant.

${ }^{a}$ MRI calcification of central nervous system at birth.

b Cognitive impairment: mental retardation scale according to the DSM-IV criteria: IQ $>70=$ normal, IQ 50-70 = moderate, IQ 35-50 = middle, IQ $20-35=$ severe, IQ $<20=$ profound.

the cochlear duct, the semicircular canals and the perilymph of infected infants [Davis et al., 1981].

Although the usefulness of cochlear implantation to CMV children with profound deafness has been fully demonstrated, there is an aspect that should be considered when counseling such children, i.e. possible coexisting central disorders and learning difficulties that may influence their speech and language development. The literature investigating the postoperative cochlear implant results of congenital CMV-deafened patients is limited. Lee et al. [2005] reported that the mean speech perception scores were 4.5 (out of 6) following implantation. Ciorba et al. [2009] reported that a cochlear implant can provide useful speech comprehension to patients with $\mathrm{CMV}$-related deafness, even if language development is poorer compared to a group of connexin-26-implanted children. Nevertheless, these results only investigate short-term outcomes while no long-term data are available on speech perception and language development.

This study is a retrospective review of 6 patients with $\mathrm{CMV}$-related profound deafness in order to investigate speech development and speech comprehension after 10 years of using a cochlear implant.

\section{Methods}

A retrospective review of the pediatric cochlear implant database was performed and 6 implantees who had been diagnosed with CMV-induced profound deafness were found. The diagnosis of CMV was made when the mother was found to have either anti-CMV IgG or IgM during pregnancy and the child was found to have CMV in urine samples or positive anti-CMV IgM titers.
The charts of these 6 children were reviewed for additional clinical information including current history, neonatal and past medical histories, imaging data and clinical examination findings. The presence or absence of prematurity, microcephaly, hepatosplenomegaly, seizure activity, psychomotor delay, leukoencephalitis and intracranial calcifications were considered as risk factors related to CMV infection that could influence the outcomes. All patients were implanted with Clarion devices (Advanced Bionics Corporation, Calif., USA). The patients' characteristics are presented in table 1.

Audiological assessment (in a preoperative period, during hearing aid use and then during cochlear implant use) included auditory brainstem responses, free field audiometry and behavioral audiometry with and without hearing aids or implant.

The speech perception abilities of children with implants were described using the speech perception categories according to the Moog and Geers Scale [Geers and Moog, 1987] in order to compare subjects across different ages and varying degrees of speech development. This is a hierarchical scale of auditory skills, ranging from no detection of speech sound to open-set speech recognition. Six levels of speech perception were then used.

Main outcome measures on language development were based on language-equivalent age (LA) i.e. age at which the average score of children with normal hearing is equal to the score of the child being evaluated. Lexical, morphosyntactic and narrative age were obtained through the norms of standardized international tests adapted for the Italian language: the Peabody test for vocabulary comprehension [Stella et al., 2001]; the Boston Naming test for vocabulary production [Riva et al., 2000]; the TROG-2 for grammar skills [Chilosi and Cipriani, 2006], and the Bus Story test for narrative skills [Renfrew, 2010]. In order to reduce bias linked to the patient's actual chronological age (CA), differences between CA and LA were analyzed as a percentage of CA with the following formula: $(\mathrm{CA}-\mathrm{LA}) / \mathrm{CA} \times 100$.

The language development was also described using the Nottingham classification categories [Allen and Dyar, 1997]. According to the Nottingham scale, three levels of speech development were then classified: (1) preverbal = no intentional verbal com- 
Table 2. Speech perception and production

\begin{tabular}{|c|c|c|c|c|c|}
\hline $\begin{array}{l}\text { Patients } \\
(\mathrm{n}=6)\end{array}$ & Detection & Recognition & Comprehension & $\begin{array}{l}\text { Auditory perceptive } \\
\text { performance }^{\mathrm{a}}\end{array}$ & Stage of language development $\mathrm{t}^{\mathrm{b}}$ \\
\hline $\mathrm{P} 1$ & $100 \%$ & $28 \%$ & $10 \%$ & 4 & transitional word sequence \\
\hline P3 & $100 \%$ & $50 \%$ & $30 \%$ & 5 & transitional word sequence \\
\hline P4 & $100 \%$ & $45 \%$ & $30 \%$ & 5 & transitional word sequence \\
\hline P5 & $100 \%$ & $80 \%$ & $80 \%$ & 6 & functional discourse \\
\hline
\end{tabular}

a Auditory perceptive performance according to the Moog and Geers Scale.

b Stage of language development according to the Nottingham classification categories.

munication (2) periverbal $=$ use of words and (3) functional $=$ use of phrases and word sequences based on morphological and syntactic rules.

The cognitive development of all patients was assessed according to the DSM-IV criteria.

\section{Results}

Included in the study were 6 children, 3 male and 3 female; 4 were symptomatic for CMV disease at birth and 2 were not symptomatic. Of the 4 children with symptomatic congenital CMV infection, 3 presented with congenital bilateral profound SNHL and 1 had progressive SNHL. Among the 2 children with asymptomatic congenital CMV infection, 1 child presented with congenital profound hearing loss and 1 had progressive hearing loss. All the patients underwent implantation with Advanced Bionic devices, all of which were fitted with digital sequential strategies ( 3 were fitted with continuous interleaved sampling and 3 with HiRes $90 \mathrm{~K}$ ). The mean age at surgery was 4.6 years, with a range of 2-10 years. The mean age of follow-up was 10 years with a range of 7-15 years. In regard to the results of the speech perception analysis, we noticed that patients affected by congenital profound hearing loss showed lower scores compared to patients with progressive hearing loss.

All the patients demonstrated the detection of speech sound. However, the recognition and comprehension results were adequate only for patient number 5 who developed profound hearing loss at the age of 10 . Concerning auditory perceptive performance, it is evident that the patients tended mostly to advance to the 5th category and recognize the words that were presented to them with the exception of patient number 1 who received the implant

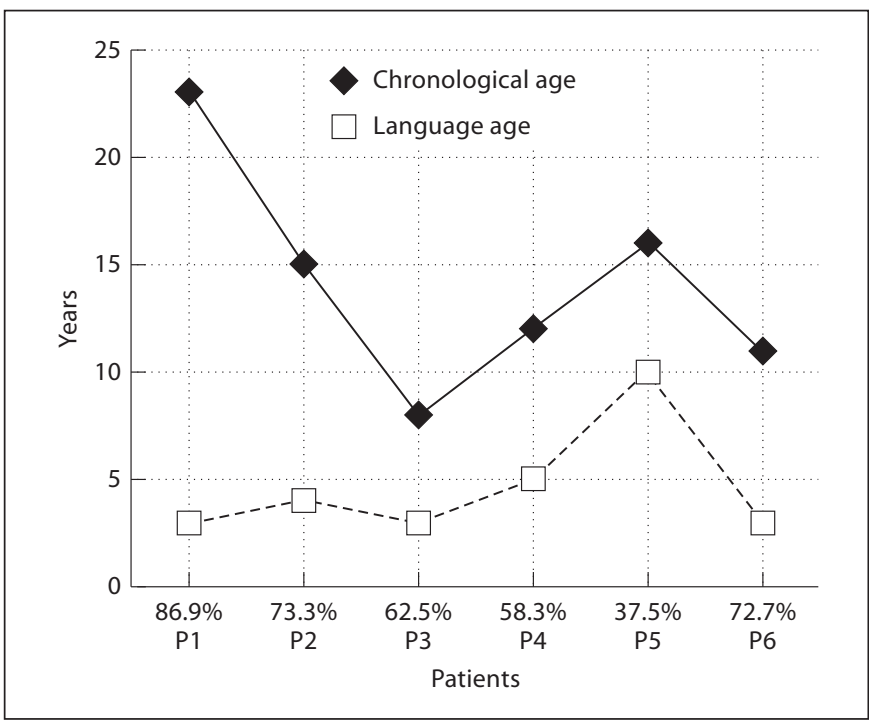

Fig. 1. The line chart shows the chronological age (solid line) compared to the language age (dashed line) of the $6 \mathrm{CMV}$ implantees. Above each patient's label, the language delay is expressed as a percentage value. $\mathrm{P} 1-\mathrm{P} 4$ = Congenital SNHL; $\mathrm{P} 5-\mathrm{P} 6$ = progressive SNHL.

later. Concerning language development, it is important to note that only 2 of the 6 patients developed a functional language with the use of phrases and word sequences based on morphological and syntactic rules. The others demonstrated the development of a preverbal or transitional language with only the use of single words (table 2). Nonverbal IQ was within the normal values for 4 patients and slightly delayed in 2 patients.

In figure 1 the chronological age of the patients and the corresponding age of language development are re- 
ported. It is shown that language delay, expressed as a percentage of CA/LA, tended to increase with time, as though the children reached a plateau during their language development.

\section{Discussion}

There are no studies in the literature regarding the outcome of cochlear implantation in CMV-infected children based on long-term follow-up. Published data have shown that cochlear implantation in children with deafness resulting from CMV infection varies widely and only early hearing rehabilitation can provide good speech perception in these patients. In this study, most of the children with CMV-related deafness were found to show an improvement in language perception and production after cochlear implantation. Asymptomatic CMV children showed better results in comparison to those who were symptomatic, and patient number 5 with progressive hearing loss showed better results compared to those with congenital hearing loss. Nevertheless, progress in these children was slower compared to their non-CMV peers [Ciorba et al., 2009; Matsui et al., 2012]. This outcome might be related to central nervous system involvement since no association between duration of deafness, age at implant and speech outcomes was evident in our study group. Yoshida et al. [2009] claim that CMV children without cognitive delay manage to bridge the gap with their non-CMV peers over a 1-year follow-up. However, in our long-term study we showed how both symptomatic and asymptomatic CMV implantees still underperformed both in speech perception and language development compared to their nonCMV peers.

In our study group, 4 of the 6 children were symptomatic at birth. Nevertheless, all children - including the asymptomatic ones - showed language delay even after 10 years of using a cochlear implant, which varied consistently despite the fact that nonverbal IQ was within normal values for most of them.

The prevalence of mental retardation in CMV patients varies from 40 to $54.5 \%$, according to the study protocol and the composition of the study group [Matsui et al., 2012; Yamazaki et al., 2012]. In our study group we found slight mental retardation in 2 of the 6 patients (33.3\%). This difference might be related to a different method used to assess mental retardation and a different followup between study groups. As far as opting for the Raven test is concerned, although some aspects might be ad- dressed in less depth, this is a well-standardized test where nonverbal intelligence can be assessed independently from coexisting motor delay and above all from verbal linguistic competence. In our experience with deaf children, this test is the easiest to administer, even in the presence of cultural differences. Furthermore, our longterm follow-up (10 years) has enabled us to observe a positive trend in the evolution of the cognitive behavior in these children, favored by the integrative use of the hearing function.

Concerning the correlation between cognitive skills and language delay, in this study group the language delay seems to be more severe than that referred to in the literature for slight mental retardation, measured in non-CMV deaf children [Meinzen-Derr et al., 2011]. This can probably be partly related to the complex neurological situation of CMV patients, and it is indeed presented in various degrees in CMV children with progressive hearing loss and IQ scores within the normal values.

In these children, language delay tends to increase over time, reaching a plateau in language skills, widening the gap between chronological and language age even in children implanted at an earlier age. Furthermore, it is also important to remember that CMV children have poor attention control and are considered more susceptible to later complications such as learning difficulties. Hence, careful observation is required on clinical course after cochlear implantation [Yoshida et al., 2009].

All these children integrated their communication handicap via the use of the visual-gestural channel at different levels, from gesture to codified Italian signs.

Present data and evidence from the literature are valuable to set realistic expectations of parents when children with CMV and profound hearing loss are considered for cochlear implantation. Multidisciplinary rehabilitation programs following cochlear implantation are essential, and a mode of language rehabilitation should be set based on the child's characteristics as early as possible.

\section{References}

Allen SE, Dyar D: Profiling linguistic outcomes in young children after cochlear implantation. Am J Otol 1997;18(suppl 6):S127-S128.

Chilosi A, Cipriani P: TCGB: Test di Comprensione Grammatical per Bambini. Pisa, del Cerro, 2006. 
Ciorba A, Bovo R, Trevisi P, Bianchini C, Arboretti R, Martini A: Rehabilitation and outcome of severe profound deafness in a group of 16 infants affected by congenital cytomegalovirus infection. Eur Arch Otorhinolaryngol 2009;266:1539-1546.

Davis LE, Johnsson LG, Kornfeld M: Cytomegalovirus labyrinthitis in an infant: morphological, virological, and immunofluorescent studies. J Neuropathol Exp Neurol 1981;40: 9-19.

Fowler KB, Dahle AJ, Boppana SB, Pass RF: Newborn nearing screening: will children with hearing loss caused by congenital cytomegalovirus infection be missed? J Pediatr 1999;135:60-64.

Geers AE, Moog JS: Predicting spoken language acquisition of profoundly hearing-impaired children. J Speech Hear Disord 1987;52:8494.

-Grosse SD, Ross DS, Dollard SC: Congenital cytomegalovirus (CMV) infection as a cause of permanent bilateral hearing loss: a quantitative assessment. J Clin Virol 2008;41:57-62.

Hagay ZJ, Biran G, Ornoy A, et al: Congenital cytomegalovirus infection: a long-standing problem still seeking a solution. Am J Obstet Gynecol 1996;17:241-245.
Hickson LM, Alcock D: Progressive hearing loss in children with congenital cytomegalovirus. J Paediatr Child Health 1991;27:105-107.

Huygen PL, Admiral RJ: Audiovestibular sequel of congenital cytomegalovirus infection in 3 children presumably representing 3 symptomatically different types of delayed endolymphatic hydrops. Int J Pediatr Otolaryngol 1996;35:143-154.

Iwasaki S, Yamashita M, Maeda M, Misawa K, Mineta H: Audiological outcome of infants with congenital citomegalovirus infection in a prospective study. Audiol Neurotol 2007; 12:31-36.

Lee DJ, Lusting L, Sampson M, Chinnici J, Niparko JK: Effects of cytomegalovirus-related deafness on pediatric cochlear implant outcomes. Otolaryngol Head Neck Surg 2005;133:900-905.

Matsui T, Ogawa H, Yamada N, Baba Y, Suzuki Y, Nomoto M, Suzutani T, Inoue N, Omori $\mathrm{K}$ : Outcome of cochlear implantation in cytomegalovirus infection or GJB2 mutation. Acta Otolaryngol 2012;132:597-602.

Meinzen-Derr J, Wiley S, Grether S, Choo DI: Children with cochlear implants and developmental disabilities: a language skills study with developmentally matched hearing peers. Res Dev Disabil 2011;32:757-767.

Renfrew C: Bus Story Test. Milton Keynes, Speechmark, 2010.
Riva D, Nichelli F, Devoti M: Developmental aspects of verbal fluency and confrontation naming in children. Brain Lang 2000;71: 267-284.

-Stagno S, Reynolds DW, Amos CS, et al: Auditory and visual defects resulting from symptomatic and subclinical congenital cytomegaloviral and toxoplasma infections. Pediatrics 1977;59:669-678.

Stagno S, Whitley RJ: Herpes virus infections of pregnancy. Part I. Cytomegalovirus and Epstein-Barr virus infections. N Engl J Med 1985;13:1270-1274.

Stella G, Pizzoli C, Tressoldi P: Peabody Test: Test Psicolinguistico. Torino, Omega, 2001.

Williamson WD, Demmler GJ, Percy AK, Catlin FI: Progressive hearing loss in infants with asymptomatic congenital cytomegalovirus infection. Pediatrics 1992;90:862-866.

Yamazaki H, Yamamoto R, Moroto S, Yamazaki T, Fujiwara K, Nasakai M, Ito J, Naito Y: Cochlear implantation in children with congenital cytomegalovirus infection accompanied by psycho-neurological disorders. Acta Otolaryngol 2012;132:420-427.

Yoshida H, Kanda Y, Takahashi H, Miyamoto I, Yamamoto T, Kumagami H: Otol Neurotol 2009;30:725-730. 